\title{
A Study on Knowledge and Awareness of Male Students of the College of Applied Medical Science at Taif University \\ Rana G Zaini*
}

College of Applied Medical Sciences, Al Taif University, Taif, Saudi Arabia

\begin{abstract}
Objective: Acquired Immune Deficiency Syndrome (AIDS) was identified in 1981, among homosexuals in the United State of America, since that time more than 60 million individuals were living with this disorder. Human immunodeficiency virus (HIV) is the causative agent of AIDS that has no cure at present. The level of knowledge about HIVIAIDS and the attitudes toward patients are crucial factors in eradicating the disease.

Methods: A cross-sectional study has been conducted for a period of two months and 155 undergraduate male students in the College of Applied Medical Sciences at Taif University participated in the study. The study aimed to assess their scientific knowledge, awareness and attitude.

Results: the survey results showed that more than half of the participants did not know the relation between AIDS and HIV and low awareness level toward the modes of HIV transmission was observed. For example $54 \%$ of students were not aware that coughing and spitting could not transmit the infection. However, many students were aware of the link between toilet seat used by a person with AIDS and HIV infection and between sharing cloths with AIDS patients and HIV with $81 \%$ and $83 \%$ respectively. Negative attitude towards HIVIAIDS persons was seen in the majority of participants.

Conclusion: This study is the first of its kind to be conducted among undergraduate male students at Taif University, and brought into limelight some important issues in relation to AIDS. This study concluded that, these students need to be more aware about HIV transmission modes and protection methods, which can be achieved by enhancing their knowledge about HIV.
\end{abstract}

Keywords: HIV/AIDS; Knowledge; Awareness; Transmission; Attitude; Male student

\section{Introduction}

In 1981, the Acquired Immune Deficiency Syndrome (AIDS) was identified among homosexuals in the United State of America USA, since that time more than 60 million individuals were living with this disorder [1]. Globally, in 2012 about 35.3 million people are living with HIV, of these approximately 17.2 million are men and 16.8 million are women $[2,3]$. This virus is caused by Human immunodeficiency virus (HIV) that has no cure at present [4].

The prevalence of AIDS showed an increase from 87,000 in 2003 to 152,000 in 2005 in the Middle East and North Africa [5]. On the other hand, at the Middle East the lowest prevalence was reported and this was related to Islam and its influence on the behaviors of the people residing in these societies [6]. Oman is one of the Arabic countries where the prevalence of HIV/AIDS is low, and this is might link to religious and cultural factors [7]. Moreover, the low rate of HIV infection within a number of other societies was highly associated to the conservative culture, which strictly forbids sexual relationships outside marriage [8].

A number of different studies have linked the AIDS occurrence and transmission to many factors such as; culture, individual age and gender [6]. In Saudi Arabia, men were more affected than women with a ratio about 3:1, this might be explained by the large number of males traveling to other countries with high prevalence of HIV. More than $60 \%$ of HIV cases reported in Saudi Arabia have been registered in Jeddah, Riyadh and Dammam. This could be attributed to high populations of these areas, in addition to the presence of illegal sex workers. The majority (46\%) of HIV/ AIDS cases reported in Saudi Arabia have been found to be associated with sexual activity, $17 \%$ has been the result of blood transmission, while the mother to child transmission accounts for $5 \%$ and $29 \%$ of the affected population denied to mention how they got it. The remaining HIV cases resulted from intravenous drug abuse (2\%) and organ transplant (1\%) [9].
Level of the community's awareness and knowledge about the HIV and their attitudes toward infected individuals: play a crucial role in controlling the disease. Recently, the major steps to prevent HIV infection are information, communication and education on HIV/AIDS that aim to target young people $[8,10]$. Media also plays a major role in elevating the level of awareness and knowledge of the community and infected patients. In contrast, neglecting HIV/AIDS and how the virus is transmitted can generate fear and prejudice towards those who are infected [10].

In India, a study done among secondary school students aged between 11 to 19 years and showed that all the students had heard about HIV/AIDS. Similar study also reported more than $50 \%$ of respondents had heard about HIV/AIDS from television and $46.9 \%$ from radio. Moreover, the awareness regarding modes of transmission including; unprotected sexual intercourse, infected blood transfusion, sharing of needles and syringes and vertical transmission of HIV from infected mother to baby was found to be significantly higher $(\mathrm{P}<0.05)$ among boys as compared to girls [11]. Similarly, 150 adolescent students from private school were the target population for the cross-sectional study performed at Kathmandu, Nepal for assessing their HIV/AIDS knowledge. The study showed that the majority of the adolescents had an average knowledge of HIV/AIDS, yet they did not know much about mode of transmission and prevention of this disease [12]. Another

*Corresponding author: Rana G Zaini, Head of the Medical Laboratories Department, College of Applied Medical Sciences, Taif University, Taif, Kingdom of Saudi Arabia, Tel: 0966 555530937; E-mail: rana_zy@hotmail.com

Received March 28, 2016; Accepted April 30, 2016; Published May 10, 2016

Citation: Zaini RG (2016) A Study on Knowledge and Awareness of Male Students of the College of Applied Medical Science at Taif University. J AIDS Clin Res 7: 574 doi:10.4172/2155-6113.1000574

Copyright: (c) 2016 Zaini RG. This is an open-access article distributed under the terms of the Creative Commons Attribution License, which permits unrestricted use, distribution, and reproduction in any medium, provided the original author and source are credited. 
study was performed at a midwestern university in the United States to assess students' knowledge, sources of information and attitude toward people living with HIV/AIDS. The study reported that the majority of students (77.3\%) were familiar with HIV/AIDS including its mode of transmission. However, $14.2 \%$ of students thought that mosquitoes could transmit HIV/AIDS [13]. In Yemen, several serious misunderstandings about HIV/AIDS were observed among university students; they believed that mothers could not transmit HIV through breastfeeding. Also, 33.9\% provided the wrong answer when asked whether the HIV virus infects only homosexuals [14]. This concurs with Al-Mazrou et al. study among students of health institutes and colleges in different regions of Saudi Arabia who were reported to have incorrect knowledge of HIV transmission. They believed that HIV could be transmitted by food and $20.2 \%$ agreed that insect could transmit the infection [9].

Al-Ghanim conducted a study at Riyadh city, on persons attending the Primary Health Care Centers and indicated that more than half of the respondents would end their friendship with HIV/AIDS-infected individuals and more than a quarter agreed that people with HIV/AIDS should be kept out from public places such as schools and workplaces [15]. Additionally, negative attitudes was reported toward people living with HIV/AIDS among Yemeni university male students while, female students showed more positive attitudes [14]. Negative attitude was observed toward HIV/AIDS individuals among a number of different studies $[9,16,17]$.

\section{Aim of the Study}

Community's awareness of HIV/AIDS and their positive attitudes toward infected patients are crucial for controlling the disease. However, health practitioner knowledge and attitude are much important because of their role as health advocate and their direct contact with infected person.

The aim of this study is to assess the level of scientific knowledge, awareness of ways of transmission among undergraduate male students in the College of Applied Medical Sciences at Taif University

\section{Methods}

This is a cross-sectional study. Study population is male undergraduate students of Applied Medical Sciences College at AlTaif University and attending the following programs, general nursing, medical laboratory, radiology and physical therapy. A paper-based questionnaire of 29 statements was developed based on previous studies research $[18,19]$ to investigate students' scientific knowledge, awareness of mode of transmission and their attitude toward infected person. The questionnaire was reviewed by two consultants and piloted on 5 students. Their recommendations and suggestions were taken in consideration. The study was conducted between January to March 2016.

\section{Data Analysis}

The responses to the first part of the questionnaire, which was about scientific knowledge was in the form of multiple choices, while the part of HIV transmission awareness was assessed by rating scale as yes, not sure or no. The last part was used to assess the student's attitude toward HIV/AIDS individuals and the respondents answer with selfscale rating as agree, not sure or disagree. The data was collected and analyzed statistically using SPSS version 16 .

\section{Ethical Consideration}

Ethical approval for this study was obtained from the ethics review committee of Applied Medical Sciences College at Al-Taif University. All information obtained at each course of the study was kept confidential.

\section{Results}

A total of 155 undergraduate male students from the College of Applied Medical Sciences completed the survey in the departments of medical laboratory, general nursing, radiology and physiotherapy). The range of respondents' age was between 19- 25 year. All the participants were Saudi nationals.

The basic knowledge about HIV/AIDS was assessed by the study's survey with nine statements. Majority of the students showed well understanding regarding the full name of HIV 81\% (126/155), while only $56 \%(78 / 155)$ were aware what does AIDS stand for (Figure 1).

This study also investigated respondents' knowledge of the HIV transmission with ten statements. Respondents' knowledge about the transmission of the disease was limited: only $46 \%$ (71/155), of

\section{Scintific Knowldge}

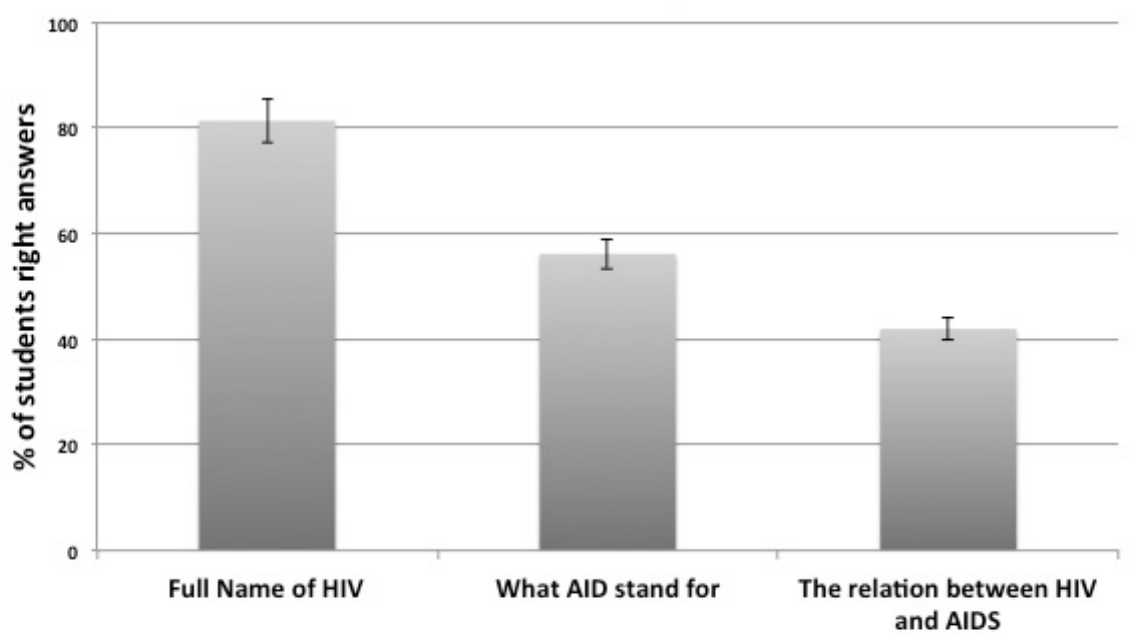

Figure 1: Scientific knowledge of HIVIAIDS among male undergraduate students of Applied Medical Sciences College at Al-Taif University. 
students were aware that coughing and spitting could not transmit the infection. Higher proportion of students know that the HIV could not be transmitted through Mosquito bite. The results also reported a high percentage of students were aware of the link between sharing drug needles and HIV (93\%) (145/155). Many students were aware of the link between toilet seat used by a person with AIDS and HIV infection (81\%) (125/155), and between sharing cloths with AIDS patients and HIV (83\%) (130/155). On the other hand, only 60\% (93/155) were aware of the fact that HIV could not be transmitted through sharing cloths with AIDS patients. Only 33\% of students had wrong believe regarding HIV transmission modes through breast milk (Figure 2).

In addition to the knowledge of the HIV transmission, the study measured students' perception and attitude toward HIV/AIDS and infected patients with sex statements. Generally, negative attitude was noticed among the majority of respondents: $32 \%$ reported that AIDS patients should not be allowed to work in places that handle food.
Unexpectedly, only $49 \%(76 / 155)$ of the students would not mind having a student or colleague with HIV in their classroom or working place while the rest had a negative attitude. Although, most of the participants (78\%) (122/155) reported their willingness to play sports with HIV positive patients. On the other hand (37\%) (57/155) believed that HIV positive patients should be isolated from the community and should stay at hospital. 58\% (91/155) of the respondents would avoid a person whose family member has AIDS. This study also indicated that $39 \%$ of the participants would feel comfortable hugging a person with HIV (Figure 3). Moreover, there were no significant differences among the attitude of the participants from the four different departments within the college $(\geq 0.5)$ when assessed with SPSS version 16 .

Since the media including television, radio, newspaper and magazines play an important role in educating people about HIV/AIDS transmission and prevention ways, this study asks the participants about their source of knowledge about HIV/AIDS and found that the media was a predominant

\section{Transmission ways}

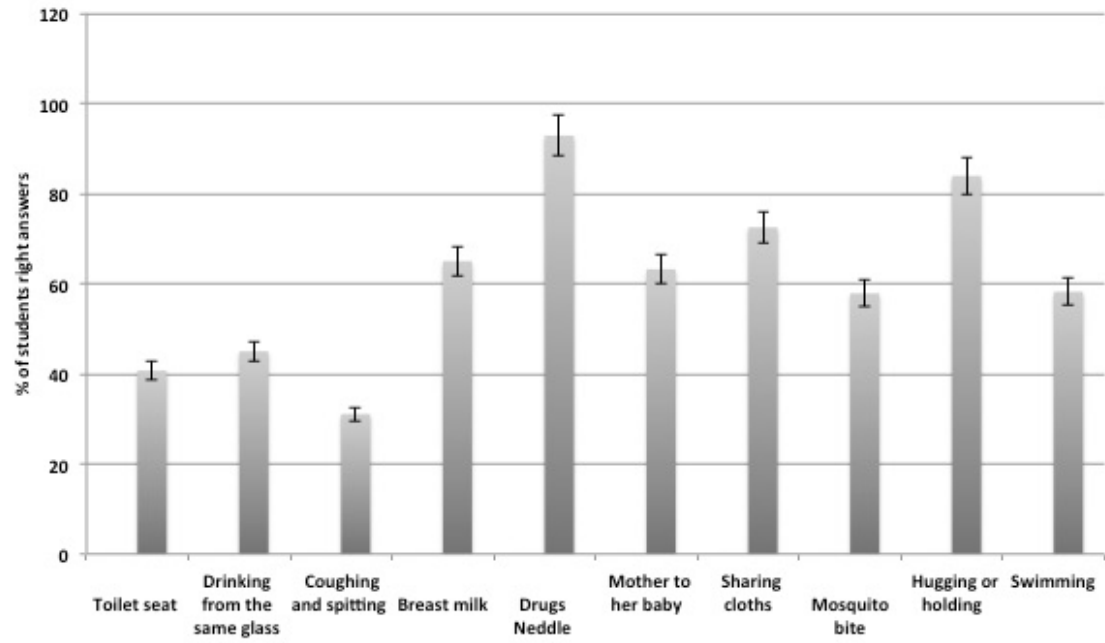

Figure 2: Transmission awareness about HIVIAIDS among male undergraduate students of Applied Medical Sciences College at Al-Taif University.

\section{Transmission ways}

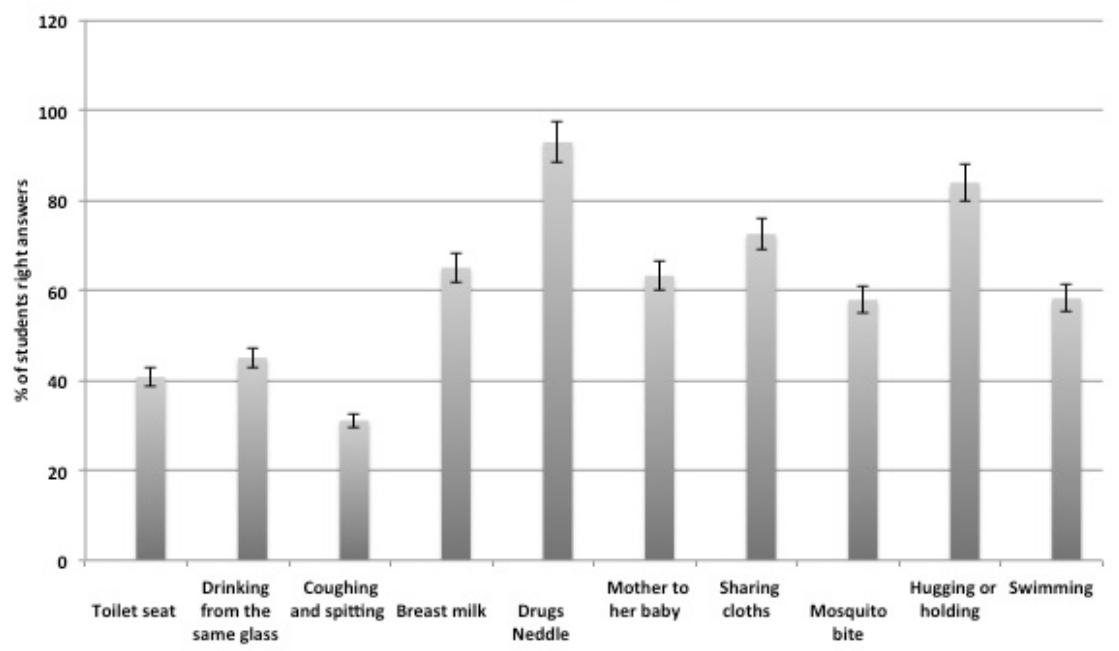

Figure 3: Positive attitude toward HIVIAIDS patients among male undergraduate students of Applied Medical Sciences College at Al-Taif University. 


\begin{tabular}{|l|c|}
\hline $\begin{array}{l}\text { Way of } \\
\text { Hearing about HIV }\end{array}$ & $\%$ \\
\hline Family & 4 \\
\hline Friends & 7 \\
\hline Media & 61 \\
\hline Others & 28 \\
\hline
\end{tabular}

Table 1: Modes of hearing about AIDS/HIV among male undergraduate students of Applied Medical Sciences College at Al-Taif University.

one among all the students with $61 \%$ followed with other ways, friends and family with $28 \%, 7 \%$ and $4 \%$ respectively (Table 1 ).

\section{Discussion}

HIV/AIDS is one of the most infectious diseases that require significant awareness, knowledge and skills. Medical students including laboratory personal, nurses and physiotherapist are expected to play a crucial role in promoting health and treating illness, as well as being health advocates. Yet the community and health care providers showed limited knowledge and negative attitude toward such a controversial issue. This study investigated male undergraduate students knowledge, awareness and attitude toward HIV/AIDS in the college of Applied Medial Sciences, Taif University, Saudi Arabia.

Generally, respondents did not demonstrate the essential scientific knowledge. $60 \%$ of the respondents did not know the relation between HIV and AIDS. Similar to our study results has been shown in a study performed on 2015 among female undergraduate students at college of Applied Medial Sciences, Taif University, which reported about $70 \%$ of female students were not aware with the link between HIV and AIDS [16]. Form the results of this study it is obvious that a true understanding of the disease is lacking. A concerted effort should be made to change the uninformed perception amongst students by implementing curriculums that will enhance their knowledge of HIV/ AIDS starting from preclinical stage which will be sustained in the clinical level.

This study has reported that $93 \%$ of the study population was aware of the fact HIV can be transmitted by sharing drug needles but most of them had incorrect perceptions about the modes of transmission through Coughing or spitting and mosquito bite (55\% and $40 \%$ respectively). Similar to our study results has been shown on female students with misunderstanding regarding the transmission of the HIV infection through mosquito bite with (61\%) [16]. Another study has reported that $64 \%$ of the study participants in south of India were unaware of the transmission through mosquito bite [10].

Positive attitude towards people living with HIV/AIDS was found to be very low and there were many items in this section, which needed attention. For example, $68 \%$ of the students reported that people with AIDS should not be allowed to work in places that handle food and $60 \%$ of the participants were feeling uncomfortable hugging a person who has AIDS. More than half of the students were avoid a person whose family member has AIDS. Negative attitude was also reported within a number of studies including; Yemeni university students [13], Saudi paramedical students [9], medical and dental students in USA [17], and in India [10].

Among all the study participants the media was a predominant source of knowledge about HIV/AIDS with $61 \%$, this was similar to the finding of other study done by Zaini [16].

Our study has brought into light some of the important issues and efforts are needed towards making medical students (Laboratory specialists, nurses, radiologists or physiotherapiests) more aware about HIV/AIDS transmissions and protections methods, which can be mainly achieved through raising the levels of knowledge about HIV/AIDS. In addition, this finding suggests that medical educators should recognize that many students have stigmatizing, highly negative attitudes toward AIDS patients. Thus, academic educators should promote greater understanding among those students. AIDS education within the faculty for health professionals should also emphasize methods for the prevention of the transmission of HIV infection among health care workers and include teaching strategies designed to deal with irrational feeling regarding AIDS.

\section{References}

1. Al-Mazrou Y, Al-Jeffri MH, Fidai A, Al-Huzaim N, El-Gizouli S (2005) HIVIAIDS epidemic features and trends in Saudi Arabia. Ann Saudi Med 25: 100-104.

2. Fact Sheet (2013) UNAIDS.

3. Avdeeva O, Lazarus JV, Aziz MA, Atun R (2011) The Global Fund's resource allocation decisions for HIV programmes: addressing those in need. J Int AIDS Soc 14: 51.

4. Getnet MK, Damen HM (2011) Level of stigma among female sex workers: comparison of two surveys of HIV behavioral data, Ethiopia. Afr Health Sci 11: 543-549.

5. Report on the Global HIVIAIDS Epidemic (2006) The Middle East and North Africa region as defined here includes Algeria, Bahrain, Egypt, Iran, Iraq Jordan, Kuwait, Lebanon, Libya, Morocco, Oman, Palestinian Territory, Qatar, Saudi Arabia, Syria, Tunisia, Turkey, the United Arab Emirates, and Yemen. Geneva: UNAIDS

6. Obermeyer $\mathrm{S}$ (2006) Prevalence of HIV in the Middle East is low but there is no room for complacency. BMJ 333: 851-854.

7. Al-Jabri A, Al-Abri (2003) Knowledge and attitudes of undergraduate medica and non-medical students in Sultan Qaboos University toward acquired immune deficiency syndrome. Saudi Med J 24: 273-277

8. Fahimi $F$ (2007) Time to intervene: preventing the spread of HIVIAIDS in the middle east and North Africa. Population reference Bureau.

9. Al-Mazrou Y, Abouzeid M, Al-Jeffri M (2005) Knowledge and attitudes of paramedical students in Saudi Arabia toward HIVIAIDS. Saudi medical journal 26: 1183-1189.

10. Sudha R, Vijay D, Lakshmi V (2005) Awareness, attitudes, and beliefs of the general public towards HIV/Aids in Hyderabad, a capital city from South India Indian journal of medical sciences 59: 307-316.

11. Srivastava M, Esam, P Mishra (2011) Adolescence Awareness: A Better Tool To Combat HIVIAIDS. National Journal of community med 2.

12. Mahat G, Scoloveno MA (2006) HIVIAIDS knowledge, attitudes and beliefs among Nepalese adolescents. Journal of Advanced Nursing 53: 583-590.

13. Inungu J, Mumford V, Younis M, Langford S (2009) HIV knowledge, attitudes and practices among college students in the United States. Journal of health and human 32: 259-277.

14. Badahdah A, Sayem N (2010) HIV-related knowledge and AIDS stigma among college students in Yemen. Eastern MediterraneanHealth Journal 16.

15. Al-Ghanim SA (2005) Exploring public knowledge and attitudes towards HIV/ AIDS in Saudi Arabia. A survey of primary health care users. Saudi Med J 26: 812-818.

16. Zaini RG, Anjum F (2015) Awareness of HIVIAIDS among Female Students Attending College of Applied Medical Sciences at Taif University. Int J Lab Med Res 2: 104.

17. Zaini R and Anjum F. (2015) Knowledge and Awareness of HIVIAIDS Infection among Female Students at Taif University, Saudi Arabia. Asian Journal of Research in Biological and Pharmaceutical Science 3: 126-132.

18. Currey J, Johnson M, Ogden B (1990) Willingness of health professions students to treat patients with AIDS. Acad Med 65: 472-474.

19. Larsen K, Serra M, Long E (1990) AIDS victims and heterosexual attitudes. J Homosex 19: 103-116. 